\title{
Correction to: NMR in pharmaceutical discovery and development
}

\author{
Raymond S. Norton ${ }^{1,2}$ (D) Wolfgang Jahnke ${ }^{3}$ (i)
}

Published online: 13 November 2020

(c) Springer Nature B.V. 2020

\section{Correction to: Journal of Biomolecular NMR https://doi.org/10.1007/s10858-020-00345-7}

The article "Boeszoermenyi A, Ogórek B, Jain A, Arthanari H, Wagner G (2020) The precious fluorine on the ring: fluorine NMR for biological systems. J Biomol NMR. https://doi.org/10.1007/s10858-020-00331-z" was written for the "Special Issue: NMR in Pharmaceutical Discovery and Development". However, unfortunately, it was published in an earlier issue of this journal owing to a publisher error. Further, the ORCID ID of author Wolfgang Jahnke is updated in the article. The original article has been corrected.

Publisher's Note Springer Nature remains neutral with regard to jurisdictional claims in published maps and institutional affiliations.
The original article can be found online at https://doi.org/10.1007/ s10858-020-00345-7.

Raymond S. Norton

ray.norton@monash.edu

$\triangle$ Wolfgang Jahnke

wolfgang.jahnke@novartis.com

1 Medicinal Chemistry, Monash Institute of Pharmaceutical Sciences, Monash University, 381 Royal Parade, Parkville, VIC 3052, Australia

2 ARC Centre for Fragment-Based Design, Monash University, Parkville, VIC 3052, Australia

3 Chemical Biology and Therapeutics, Novartis Institutes for Biomedical Research, Virchow-16.3.249, 4002 Basel, Switzerland 